FACULDADE DE CIÊNCIAS ECONÔMICAS DA UFRGS
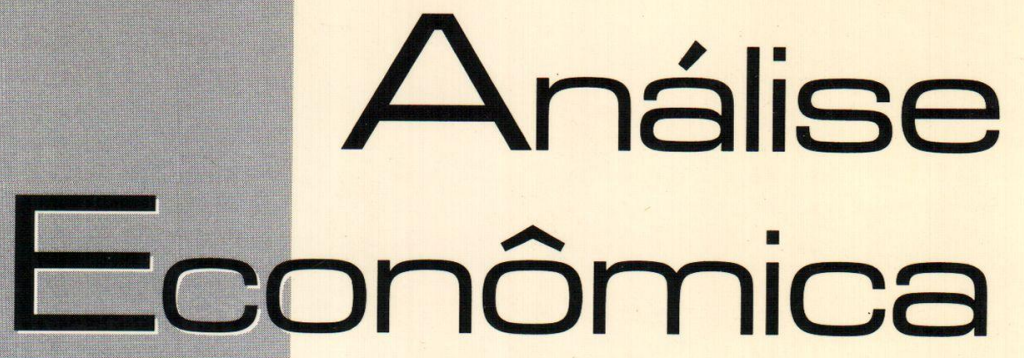

A CIÉNCIA ECONOMICA NA EUROPA E NOS Estados Unidos: PluRAlismo Versus MONISMO

ANTONio Maria da SiLveira

A EXPANSÃO DO COMERCIO MUNDIAL: IMPLICACOO ES SOBRE A HIPÓ TESE DE CONVERGENCIA

MANOEL BOSCO DE ALMEIDA

O SETOR AGRICOLA NA ÁREA DE LIVRE COMERCIO DAS AMÉRICAS: DESAFIOS DA INTEGRAÇÃO REGIONAL

PAULO D. WAQUIL.

PEQUENOS E MEDIOS FABRICANTES DE BENS DE CAPITAL FRENTE AS MUDANÇAS NA ECONOMIA BRASILEIRA

HOYEDO NUNES LINS

RISCOS NA ATIVIDADE BANCÁRIA EM CONTEXTO DE ESTABILIDADE DE PREÇOSE DE ALTA INFLAÇÃO

LUIS FERNANDO RODRIGUES DE Paula

O FIO DA NAVALHA DE HARROd EA RESPOSTA DA ESCOLA DE CAMBRIDGE MARIo AUGusto Bertella

A DINAMMICA FINANCEIRA INTERNACIONAL E A TENDENCIA Ã DOLARIZAÇÄO DAS ECONOMIAS LATINO-AMERICANAS

MARCOS ANTONIO MACEDO CinTRA

TEMPORALIDADE DA RIQUEZA - TEORIA DA DINAMMICA E FINANCEIRIZAÇÃO DO CAPITALISMO - RESENHA

Gentil Corazza

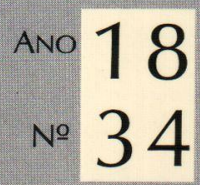


Universtode Federal do Rio Grande do Sul

Reitora: Prof ${ }^{a}$. Wrana Maria Panizzi

Faculdade de Crências Econômicas.

Diretora: Prof ${ }^{4}$. Otilia Beatriz Kroeff Carrion

Centro de Estudos e Pesquisas Econômicas

Diretor: Prof. Fernando Ferrari Filho

Departamento de Ciências Económicas

Chefe: Prof. Luiz Alberto Oliveira Ribeiro de Miranda

Departamento de Crências Contábeis e Atuariais

Chefe: Prof. João Marcos Leão da Rocha

Curso de Pós-Graduação em Economia

Coordenador: Prof Marcelo Savino Portugal

Curso de Pós-Graduação em Desenvolvimento Rurai

Coordenador: Prof Carlos Guilherme A. Mielitz Netto

Consel.ho Eomorial: Achyles B. Costa, Aray M. Feldens, Carlos A Crusius, Carlos G. A Mielitz Netto, Eduardo A. Maldonado Filho, Eduardo P. Ribeiro, Eugênio Lagemann, Fernando Ferrari Filho, Gentil Corazza, Jan A. Kregel, Marcelo S. Portugal, Nali J. Souza, Otília B. K Carrion, Paulo A. Spohr, Paulo D. Waquil, Pedro C. D. Fonseca, Philip Arestis, Roberto C. Moraes, Ronald Otto Hillbrecht, Stefano Florissi, Eleutério F. S. Prado (USP), Fernando H Barbosa (FGV/RJ), Gustavo Franco (PUC/RJ), João R. Sanson (UFSC), Joaquim P. Andrade (UnB), Juan H. Moldau (USP), Paul Davidson (Univ of Tennessee), Werner Baer (Univ. of Mlinois)

Comissāo Eoitonial: Eduardo Augusto Maldonado Filho, Fernando Ferrari Filho, Gentil Corazza, Marcelo Savino Portugal, Paulo Dabdab Waquil, Roberto Camps Moraes.

EdITor: Gentil Corazza

EdrTor Adjunto: Pedro Silveira Bandeira

Secretarus: Márcio Souza de Vargas

REVISĩo de teXtos: Vanete Ricacheski

Fundador: Prof. Antônio Carlos Santos Rosa

Os materiais publicados na revista Análise Econômica são da exclusiva responsabilidade dos autores. É permitida a reprodução total ou parcial dos trabalhos, desde que seja citada a fonte. Aceita-se permuta com revistas congêneres. Aceitam-se, também, livros para divulgação, elaboração de resenhas e recensões. Toda correspondência, material para publicação (vide normas na terceira capa), assinaturas e permutas devem ser dirigidos ao seguinte destinatário:

Prof. Genth Corazza

Revisia Anáxise Econômica - Av. João Pessoa, 52 CEP 90040-000 PORTO ALEGRE - RS, BRASIL

Telefones: (051) 316-3513 316-3440 - Fax: (051) 316-3990 rae@vortex.ufrgs.br

Análise Econômica

Ano $18, n^{\circ} 34$, setembro, 2000 - Porto Alegre

Faculdade de Ciências Econômicas, UFRGS, 2000

Periodicidade semestral, março e setembro

1. Teoria Econômica - Desenvolvimento Regional Economia Agrícola - Pesquisa Teórica e Aplicada -

Periódicos. I Brasil

Faculdade de Ciências Econômicas,

Universidade Federal do Rio Grande do Sul.

CDD 330.05

CDU $33(81)(05)$ 


\section{A ciência econômica na Europa e nos Estados Unidos: pluralismo versus monismo}

Antonio Maria da Silveiral

Resumo: Procuramos formalizar os termos da contenda, uma versão atual da Methodenstreit, usando Lakatos como entendido por Feyerabend (uma síntese de Popper e Kuhn). Percebemos a ciência da UE desenvolvida segundo uma concepção ampla, englobando a economia abstrata, social e sua arte, como desenvolvemos em nosso programa de pesquisa sobre a Indeterminação de Senior. Percebemos a dos EUA especializada no componente normal, abstrato e aplicado, do programa neoclássico. Ambas podem ser bem avaliadas quanto à produção, desde que os critérios atendam às diferenças de escopo e método. Postergando análise mais profunda do caso europeu, concentramo-nos no estadunidense. O pluralismo, a concorrência de outras escolas, com jornais e editores independentes, parece desprezível, comprometendo sua objetividade. A economia social, com seus departamentos interdisciplinares, parece encontrar-se excluída da comunidade, explicando a generalidade do vício ricardiano.

Palavras-chave: Ciência econômica, pluralismo, monismo.

\section{Introdução}

Analisamos a controvérsia entre a ciência econômica européia e a estadunidense em termos de uma concepção ampla da ciência e do modelo estrito de Lakatos. A controvérsia é sobre o escopo e o método da economia, podendo ser vista como versão moderna da Contenda do Método, o Methodenstreit. Centraliza-se na União Européia (EU): sua crescente integração continental, o contraste de sua produção científica com a dos Estados Unidos (EUA) e, particularmente, seu número bem menor de laureados Nobel constituem-se nos elementos deflagradores da contenda.

A concepção ampla que utilizamos é o quadro geral de referência de nosso programa de pesquisa sobre a natureza incompleta do conhecimento científico e a impropriedade de sua aplicação direta na prática, um aprofundamento do que Schumpeter denominou vício ricardiano. Passamos a uma rápida apresentação, a qual será complementada ao longo do texto.

\footnotetext{
${ }^{1}$ Professor-Visitante do Instituto de Economia da Universidade Federal de Uberlândia Uma versão anterior e mais longa deste artigo foi apresentada no V Encontro de Economia Política, em Fortaleza, $20-23 / 6 / 2000$.
} 
O nível de evolução atingido pela economia já mostra, como nas ciências naturais, duas esferas de abstração bem identificáveis nas teorias positivas (sobre o que é). Uma economia abstrata em que, como na física, os especialistas têm a motivação no conhecimento pelo conhecimento, o comprometimento na formalização hipotético-dedutiva e a linguagem na lógica formal.

$\mathrm{Na}$ esfera aplicada, que denominamos economia social, especialistas têm sua motivação num conhecimento diretamente aplicável. O comprometimento deles encontra-se então na formulação de teorias realistas, teorias que levam em conta todos os fatores gerais e necessários que se mostram relevantes na prática. Não podem assim ignorar instituiçôes e elementos não-econômicos apenas por não serem matematicamente tratáveis ou quantificáveis.

Predomina a lógica da linguagem natural, a qual se reduz à lógica formal quando a simplicidade do fenômeno o permite. Este é o caso, freqüiente nas ciências da engenharia, quando existe a possibilidade de controlar ou, mesmo, de moldar o fenômeno na prática. Decresce então a relevância de suas dimensões não-econômicas, assim como de cambiantes especificidades, como costuma acontecer em finanças. Reservamos para tais situações a denominação economia aplicada, como caso-limite da economia social.

No geral, a arte da ciência econômica e a prática exigem o tratamento individualizado de cada ocorrência do fenômeno, pois especificidades podem ser mais relevantes do que suas causas universais e necessárias. Schumpeter (1986, p. 540-1) identificou e batizou o vício ricardiano:

Eles [Senior, Mill e outros] quiseram apenas dizer que as questões de política econômica envolvem sempre tantos elementos não-econômicos, que seu tratamento não deve ser feito na base de considerações puramente econômicas[...] poder-se-ia apenas desejar que os economistas daquele (como de qualquer outro) período nunca se esquecessem deste toque de sabedoria - nunca fossem culpados do Vício Ricardiano.

Colocando o autor em nossa concepção ampla, o vício está no hábito de derivar proposições normativas a partir da economia abstrata, ou mesmo de derivá-las da social sem atenção para as especificidades que individualizam as ocorrências do fenômeno.

Duas outras passagens em Schumpeter (ib., p. 473, 1171) podem sugerir que, na caracterização do vício, ele também incluísse a maneira em que Ricardo e Keynes teorizavam, mas a conexão feita com "Senior, Mill e outros" mostra claramente que essa restrição não predominava em seu pensamento. Indo à própria referência que faz a Senior (1938, p. 3): 
Mas as conclusões dele [do Economista Político], não importando a generalidade ou verdade que encerrem, não o autorizam a adicionar uma simples sílaba de conselho[...] Decidir, em cada caso, até quando as conclusões do Economista Político devem gerar ações, pertence à arte de governo, arte para qual a Economia Política é apenas uma das muitas Ciências subservientes.

Mill (1877, p. 152, 155) segue Senior, generalizando-o:

Cada arte pressupõe, não uma ciência, mas ciência em geral; ou, pelo menos, muitas ciências distintas [...] Ninguém que busque estabelecer proposições para orientação da humanidade pode dispensar, não importando suas realizações científicas, o conhecimento prático sobre as maneiras em que afazeres do mundo são de fato conduzidos, e uma ampla experiência pessoal com idéias, sentimentos, e tendências intelectuais e morais de fato existentes em seu país e em sua própria época.

Nossa pesquisa reconhece a constelação de ciências que se desenvolveu desde então, assim como o nível de abstração cada vez maior das ciências puras, particularmente da economia. Reconhece ainda que o entrelaçamento de muitas ciências distintas ocorre no nível científico, no nível da ciência positiva. Formulamos assim o que chamamos de Indeterminação de Senior, sendo o vício o hábito de não respeitá-la:

As proposições da economia abstrata, não importando a generalidade ou verdade que encerrem, não autorizam conclusões normativas, mas não podem ser ignoradas. A economia social positiva entrelaça teorias econômicas abstratas e todas as ciências sociais, mas com relevância variável. Conclusões normativas são deriváveis de proposições da economia social, mas são ainda qualificáveis pelas especificidades de cada caso.

Schumpeter (ib., p. 540-1) sugere que a atenção dos economistas foi desviada deste toque de sabedoria para a questão de juízos de valor, desde Cairnes, Sidgwick e Weber. Antes deles, não se reconhecia que derivações na forma de "o que deve ser" requerem ainda juízos extracientíficos. Vínhamos acrescentado esse ponto na série de artigos sobre a indeterminação, desde os primeiros. Devemos postergá-lo, contudo, pois ele não estava em Senior e Mill, e sua incorporação vem aqui provocando o mesmo desvio de atenção ${ }^{2}$.

A concepção estrita da ciência que utilizamos é o modelo de Lakatos (1980). Está voltado para teorias abstratas, abrangendo apenas as teorias

\footnotetext{
${ }^{2}$ Em Silveira (1999), apresentamos detalhadamente as realizações do nosso programa de pesquisa sobre a Indeterminação de Senior, cujo marco localizamos em Silveira (1991). O presente artigo e os seguintes, que o complementam, têm precedentes imediatos em Silveira (1998a) e em um trabalho incompleto, escrito na Universität Hohenheim, Silveira (1998b), quando lá estivemos como ProfessorVisitante.
} 
aplicadas logicamente integradas ou em processo de integração. Especificamente construído em termos da física como paradigma, incluindo a física experimental e a física aplicada, o modelo aplica-se bem às paralelas esferas de conhecimento da ciência econômica.

Na seção 1, expomos a contenda através de uma revisão de três ensaios, Frey e Eichenberger (1992), Portes (1987) e Kolm (1988), os quais caracterizam as diferenças e tipificam posicionamentos. Procuramos, na seção 2, ampliar suas evidências, perspectivas e classificações com apoio em Schumpeter e Hayek, assim como na filosofia da ciência, num entrelaçamento de Popper, Kuhn, Lakatos e Feyerabend.

Passamos então, na seção 3, a uma análise do Relatório Krueger sobre a formação do economista nos EUA. Vamos gradualmente montando nossa interpretação, ao conduzirmos a exposição ao longo dessas seções. Além de conectar, com a literatura filosófica, as distintas maneiras em que se vê a ciência econômica na UE e nos EUA, concentramos o esforço nas questões do vício ricardiano e do monismo.

Deixamos para um artigo seguinte, por falta de espaço, a revisão de quinze ensaios, reunidos pelos editores da revista KYKLOS em número especial de 1995, intitulado "Existe uma Ciência Econômica Européia?". Dois outros autores responderam ao convite para comentários sobre esse número e são também revistos, num total de 21 participantes dessa contenda.

Ao assim segmentarmos o trabalho, buscamos separar também as grandes questões envolvidas, postergando, por exemplo, o tratamento da dificuldade de alguns contendores com a própria pergunta dos editores, assim como uma análise compreensiva dos efeitos perversos dos sistemas de incentivos e de critérios de avaliação da ciência. Antecipamos, por outro lado, um ou dois pontos mais relevantes para os temas aqui discutidos, mas procurando fazê-lo em notas de rodapé . $^{3}$

\section{Posicionamento das questões}

Frey e Eichenberger (1992) afirmam que tipos e tamanhos dos mercados determinam as distintas configurações acadêmicas da ciência econômica na UE e nos EUA, ao estabelecerem incentivos e critérios de avaliação e, assim, as correspondentes produções científicas e práticas.

\footnotetext{
${ }^{3}$ Nosso objetivo final é a análise da ciência econômica no Brasil, particularmente no período 199697, quando ocupamos a secretaria-executiva da ANPEC (Associação Nacional dos Cursos de PósGraduação em Economia) e também participamos da Comissão de Especialistas de Ciências Econômicas do Ministério da Educação, Comissão que coordenamos em 1999. Esse objetivo pode estar inconscientemente influenciando nossa análise
} 
Os autores prevêem que europeus se aproximarão dos estadunidenses, com redução da dessemelhança e do dissenso, em virtude do aumento de mercado com a ascendente integração na UE - não o denominam processo de americanização nem se posicionam valorativamente sobre a previsão.

O mercado europeu é bem segmentado pelas fronteiras lingüísticas e institucionais, sendo os segmentos pequenos para que a concorrência possa forçar a desregulamentação governamental. O estadunidense é impessoal, competitivo e "suficientemente grande para definir seus próprios critérios, obedecendo a uma forte dinâmica interna" (ib., p. 216).

Europeus cultivam uma formação teórica ampla, o conhecimento de instituições e dos problemas econômicos locais, assim como a atuação política. Estadunidenses trabalham no "nível abstrato, não institucionalmente específico, mas teoricamente especializado" (ib., p. 217).

Numa primeira colocação dos autores em nossos termos, europeus têm mais sucesso dentro do sistema de avaliação que abrange a economia abstrata, social e sua arte, enquanto estadunidenses também se mostram mais produtivos segundo avaliação restrita à economia abstrata e aplicada, as quais podem ser englobadas na denominação de economia pura. Assumimos essa percepção como representativa da realidade.

A avaliação européia compreende, além de posições políticas alcançadas, vários indicadores, como a formação, a escola de pensamento e o departamento de exercício da carreira, as posições hierárquicas ocupadas, títulos honoríficos recebidos, participações em conselhos e até desempenho de ex-alunos.

Portes (1987) é referência dos autores na exposição do sistema de avaliação estadunidense. Ele aplica, contudo, os mesmos critérios para avaliação dos europeus, sem quaisquer ajustes (Frey e Eichenberger, ib., p. 217 8)! Escreve um trabalho de posicionamento (o que deve ser), advogando, como política educacional européia para a ciência econômica, nada mais do que a simples americanização ${ }^{4}$.

Portes evidencia a dominância estadunidense usando indicadores e escores, como o número de laureados-Nobel (14 x 10), de entradas no Who's

\footnotetext{
${ }^{4}$ Portes escreveu sob encomenda da European Science Foundation Standing Committee for the Social Sciences e o trabalho foi publicado por iniciativa da EER (Revista Européia de Économia). Os editores afirmam que "um mérito do artigo está certamente em seu esforço de fundamentar com números e fatos as asserções que são feitas". Comprometem-se a considerar para publicação outros trabalhos "semelhantemente sucintos e cerradamente argumentados" (EER 1987, p. 1.329).
} 
Who in Economics $(65 \% \times 29 \%)^{5}$, de "fellows" na Sociedade de Econometria $(61 \% \times 30 \%)$, de artigos resumidos no Journal of Economic Literature (apenas 25\% de europeus em 1984-85), de páginas padronizadas das principais revistas, de citações, etc.

$\mathrm{O}$ autor entende a ciência econômica na concepção estrita, economia pura, e restringe-se aos termos em que é exercida nos EUA, mesmo quando fala do economista na prática. Não faz sequer menção sobre a importância do tratamento interdisciplinar de problema algum, muito menos referências à economia social.

Pelo contrário, aponta história, sociologia e direito, em oposição à economia, como campos de conhecimento mais especificamente dependentes do contexto ou país. Indica, contudo, essa dependência na economia aplicada, como se esta não fosse parte do que chama ciência econômica (ib., p. 1.337).

Usa de fato confusamente o termo aplicado, nele englobando a arte da economia e a sua prática, assim como a econometria. Reservamos a denominação arte da ciência para os estudos de caso, exemplificáveis na completude conduzida por Myrdal, e para a história econômica, sendo Schmoller um exemplo igualmente maior. São trabalhos científicos nitidamente acadêmicos.

Diferenciam-se da ciência pura e da social pelo reconhecimento das cambiantes especificidades em ocorrências distintas de um fenômeno e pela visão de que cada ocorrência é um caso. A motivação está no entendimento compreensivo de cada caso. Diferenciam-se ainda da prática pelo comprometimento com a aplicação de teorias ou, mesmo, pelo esforço para o desenvolvimento a longo prazo delas.

A prática da economia não é obviamente um trabalho científico, mesmo quando conduzida por acadêmicos e quando bem informada pela ciência, como o período governamental de Erhard. O comprometimento está no sucesso da política, pública ou privada. A motivação é no saber como, e o interesse no saber porque reduz-se a aperfeiçoamentos diretos que tal conhecimento da ciência e de sua arte possa trazer para a prática ${ }^{6}$.

O econometrista que trabalha na busca de pontos de checagem de teorias abstratas está fazendo economia abstrata, assim como o físico experimental faz

${ }^{5} \mathrm{M}$. Blaug and $\mathrm{P}$. Sturges, eds. Wheatsheaf, 1983

' Baumol (1995, p. 188-9), dentre os autores que revimos, enfatiza, como fazemos, a atitude do cientista como critério para sua classificação numa categoria ou noutra Cabe antecipar, por outro lado, que a atividade prática, apesar de não científica, pode estar incluída na avaliação de mérito do acadêmico que a conduz, quando se entende a ciência numa concepção ampla, como acontece na UE. Há efeitos positivos e negativos, como veremos no próximo artigo. 
física. Apresentar seus pontos de checagem como previsões para o que ocorrerá na prática é, geralmente, vício ricardiano em estágio grave. Vale o mesmo, com menor gravidade, para o trabalho econométrico em teorias aplicadas.

Tem-se igualmente o vício se, na prática, uma análise apenas econômica da conjuntura econômica é apresentada como completa, compreensiva. Essa asserção é compatível com Hayek (1975, p. 252-53), quando afirma que a economia se reduz à previsão de padrões de ocorrência, de evento típico não de evento singular. Vale citar Marshall, como citado em Groenewegen (1990, p. XIV), numa bela e sucinta formulação do que chamamos indeterminação de Senior: “A Economia Política raramente responde qualquer questão social, assim como qualquer questão social raramente pode receber respostas independentemente da Economia Política."

As teorias econômicas puras, incluindo os trabalhos empíricos que se baseiam exclusivamente nelas, são parciais, são cenários lógicos para casoslimite da realidade. Popper afirma que as teorias físicas são verdades temporárias. Seguindo-o, teorias econômicas não passam de meias-verdades temporárias (Silveira 1994b, p. 208).

Quatro são as causas a que Portes (ib., p. 1335-7) atribui o “atraso europeu", cabendo citá-las com ligeira indicação de suas propostas políticas. A lingua é a primeira e, no aplauso à prática da Associação Econômica Européia, sua proposta está em estímulos para o uso exclusivo do inglês.

O método é a segunda e advoga, pragmaticamente, o transplante completo da prática estadunidense, apesar de reconhecer as limitações do "modernismo" e a retórica em sua adoção, explicitamente nos termos de McCloskey (1983) 7 .

Advoga também o transplante do "treinamento", a terceira causa, propondo por volta de dez centros europeus de excelência na oferta de programas de doutoramento, devendo o "treinamento de $\mathrm{PhD}$ ", de europeus nos EUA, simultaneamente prosseguir para a capacitação docente da UE.

Entende ser a proposta realista em face dos cerca de quinze centros de primeiro nível nos EUA. Reconhece a limitação "na maturidade e no senso de relevância" do estudante estadunidense, mas descarta a falha em termos da superioridade nas mais avançadas técnicas de pesquisa (ib., p. 1.336).

Finalmente, o dinheiro é a quarta causa, no que se estende o autor apenas nos problemas salariais da academia européia. Advoga, em particular, um salário competitivo com o estadunidense, não duas ou três vezes menor como quando escreve (1987).

\footnotetext{
${ }^{7}$ Discutimos a retórica no artigo seguinte, como exposto na introdução.
} 
Há uma admoestação no estilo das famosas palavras do Presidente Kennedy - "O economista deve sempre perguntar ambas, o que pode ele fazer pelo mercado, no sentido de aperfeiçoar o seu funcionamento, e o que o mercado deve fazer por ele"' (ib., p. 1.339) -, seguindo-se, dentre outras, a sugestão para que aumentos salariais para a academia sejam conseguidos, junto a cada governo, pelos colegas assessores de políticas públicas!

Kolm (1988) assumiu uma réplica a Portes (1987), em trabalho de posicionamento não menos valorativo ${ }^{8}$. Fala do ponto de vista europeu, mas com referência explicitamente francesa, e manifesta a expectativa de que também o façam colegas dos outros países. Para o autor, "A americanização, em nome da comunicação, não é uma trajetória possível para a Europa, pois, no final, não haveria mais justamente a Europa" (ib., p. 211-2).

Da leitura dos três trabalhos, fica a impressão de que Frey e Eichenberger (1992) esforçaram-se por manter uma análise mais positiva, tendo em perspectiva as valorações dos dois trabalhos precedentes. Kolm começa pela inversão das asserções de Portes, ao acrescentar uma informação aos "números e fatos" que as fundamentam.

Estatísticas de Portes estimam apenas a quantidade da produção acadêmica em inglês. Como a comunidade de língua inglesa na UE é quatro vezes menor, sua esperável produção expressa nessa língua não seria mais do que um quarto. Logo, o que "clama explicação é que essa taxa é, de fato, muito mais favorável à Europa" (ib., p. 207).

Depois de elaborar sobre essa inversão, o autor passa às limitações qualitativas dos números e fatos de Portes, numa apreciação relativa da produção estadunidense. Aponta as centenas de publicações com contribuição desprezível, as milhares fundamentadas em hipóteses absurdas, irrealistas ou ingênuas, salienta a ignorância revelada sobre o lado não econômico da realidade, etc.

À "incultura abismal" sobre outras ciências sociais no trabalho positivo, Kolm (ib., p. 209) adiciona em relação ao normativo, "Dar conselhos sem a correta visão do que pode e do que não pode ser mudado não é uma boa economia aplicada" - diríamos, não é boa economia na prática.

\footnotetext{
${ }^{8}$ Ao contrário de Portes, Kolm submeteu seu trabalho para publicação, chegando nele a afirmar que a E.ER, em virtude de impor o uso exclusivo do inglês, "não tem o direito de usar o adjetivo 'européia', nem lógica, nem moral e nem mesmo legalmente talvez" (ib., p. 208). Os editores da EER 32 ( p. 207) elegantemente notam que se trata de um "economista altamente produtivo, cujas visões sobre o papel do inglês e da matemática nada devem a uma falta de habilidade no manejo das duas linguagens". De fato, Baumol (1995, p. 189) o destaca, ao lado de Malinvaud, Mäler e Grandmont, ao falar sobre os economistas europeus "com habilidade e originalidade na aplicação da matemática à teoria econômica".
} 
Tem-se uma convicção de que a economia social é indispensável ou, mesmo, de que se constitui no núcleo da ciência, seguida de uma clara acusação do vício ricardiano na literatura estadunidense, faltando apenas designá-lo como tal. A preocupação com o vício ou com essa, como o diz, "doença" nas publicações aparece enfaticamente (ib., p. 211):

... é óbvia a demonstração de que não se pode explicar crescimento e produtividade, rigidez salarial e desemprego, o custo da inflação, interações em mercados ou dentro de organizações, expectativas, comportamento em relação ao risco, relações e instituições econômicas internacionais, o preço do petróleó, etc., ou que não se pode dizer o que deve ser feito, sem conhecer mais do que os economistas estadunidenses atualmente conhecem sobre normas, anomia, auto-referência, racionalidade, motivação, imitação, psicologia cognitiva, social e genética, teoria ética dos contratos sociais, filosofia social e histórica das mundivisões, história das mentalidades, etc.

Frey e Eichenberger (ib., p. 218-9) estendem-se no ponto, sem a ele se referirem também como vício ricardiano. Apontam-no como diferença entre economistas europeus e estadunidenses, mas voltados para a explicação do dissenso entre ambos. Este é revelado, de forma estatisticamente significativa, nas respostas a uma série de proposições construídas por James Kearl et al.

Não tendo conhecimento institucional, estadunidenses respondem-nas como se fossem questões de livros-texto, "exercícios acadêmicos", enquanto as respostas européias são localizadas e datadas, estão inseridas em seus diferentes contextos institucionais. Assim, o menor apoio europeu para o programa de renda mínima deve-se a expectativas de inchações dos governos ou de solapamentos por grupos de interesse negativamente afetáveis.

Como causa das "doenças" da ciência estadunidense, Kolm (ib., p. 209) aponta primeiro dois traços culturais, a imitação (derivada do conformismo, da falta de história, etc.) e o que prefere dizer com as palavras de David McClelland, professor de Harvard, "Ele [o behaviorismo] apetece à índole estadunidense. É de muito simplismo mental, não possui intelectualidade alguma, mas uma espécie de qualidade de engenharia".

As duas outras causas estão no sistema de incentivos - "produzir depressa dentro da recebida estrutura epistemológica e ideológica" (ib., p. 210) - e nas idiossincrasias metodológicas da economia - essencialmente, a possibilidade da econometria, com estratagemas geralmente aceitos e com o uso das pseudomedidas econômicas (Georgescu-Roegen 1967, p. 122), corroborar ou refutar praticamente qualquer teoria.

Diríamos, qualificando, mostrar o mesmo ponto de checagem como uma das evidências acumuláveis de corroboração ou, alternativamente, de 
refutação, quando no confronto com outra teoria ou programa de pesquisa. Acrescentaríamos também que se pode dar algum desconto no valor da evidência, segundo o grau de artificialismo na sua construção ${ }^{9}$.

Concluímos por assumir o vício ricardiano como traço da ciência estadunidense e passamos a trabalhar essa contenda, usando a filosofia da ciência como "caixa de ferramentas". Dentre outros aspectos, veremos que a redução do dissenso na ciência hodierna, aspiração implícita em Frey e Eichenberger (ib., p. 218-9), é traço de degeneração, não de maturidade da ciência.

\section{Uma ampliação das evidências e perspectivas}

Kolm vai bem mais longe, mas evoca o que Schumpeter (1986, p. 471-2) afirmou sobre Ricardo:

... embora [Ricardo] viesse de um lar culto, era tudo menos alguém educado no sentido escolástico[...] Não é porque [Ricardo] teria outra filosofia, mas porque aquela mente ocupada e positiva não tinha filosofia alguma[...] Similarmente, não tinha sociologia alguma[...] Quanto a estas [às conclusões normativas de Ricardo], nós sentimos a falta de percepção sobre os poderes que motivam o processo social e, adicionalmente, a falta de senso histórico ${ }^{10}$.

Essas faltas constituem-se, para o autor, nas causas do vício ricardiano. $O$ testemunho sobre seus estudantes nos EUA, que vem associado em nota de rodapé, traz substantivo apoio para nossa visão sobre a ciência lá praticada, pois os estudantes de então são os pesquisadores mais idosos do período em foco:

Não acredito que Ricardo tenha feito muita leitura em história. Mas não é isso que quero dizer. O problema com ele é semelhante ao problema que tenho, a este respeito, com meus estudantes estadunidenses, os quais trazem uma abundância de material histórico forçado pelas goelas abaixo. Mas não serve a nenhum propósito. Não possuem o senso histórico, o qual não pode ser dado por montante algum de estudo fatual. Esta é a razão de ser tão mais fácil fazer deles teóricos do que economistas.

Schumpeter não está reconhecendo os especialistas teóricos, certamente os abstratos, como economistas. É uma apreciação importantíssima,

\footnotetext{
${ }^{9}$ Curiosamente, a posição de Kolm lembra a de Stigler (1959, p. 531), o qual afirma que a ciência econômica fornece instrumentos para a competente defesa das mais opostas posições na prática da economia. A questão das pseudomedidas é tratada em nosso artigo seguinte.

${ }^{10}$ Onate (1999, p 89) cita Hutchison, numa citação de Marshall, apontando a peculiar posição de Ricardo na literatura econômica inglesa
} 
mas há que se investigar bem a matéria para assim caracterizar sua posição na história do pensamento econômico.

Tal investigação não nos é necessária no caso de Hayek (1969), o qual, além de especular sobre um possível erro quando da separação entre os ensinos de economia e direito (ib., p. 251), também apresenta seu testemunho sobre o estudante estadunidense:

... tenho esperança de novamente encontrar [em Freiburg] esse espírito de abrangente curiosidade intelectual e de aventura espiritual de que me lembro dos meus tempos de estudante em Viena e que, se não desconhecido, é pelo menos muito mais raro nas universidades estadunidenses. Para aqueles que sentem que os problemas de nosso campo são realmente importantes, o estudo especializado precisa ser o começo de uma luta para alcançar uma compreensiva filosofia da sociedade (ib., p. 268).

... quem é apenas um economista não pode ser um bom economista. Muito mais do que nas ciências naturais, é verdade que nas ciências sociais raramente há um problema concreto que possa ser adequadamente respondido na base de uma única disciplina especial (ib., p. 267).

É nessa linha que se coloca Kolm. Não se trata, naturalmente, da rejeição da ciência pura. Repudia-se o vício ricardiano e a exclusividade da economia pura, abstrata e aplicada. Indo mais longe em nossa identificação desta linha de pensamento, rejeita-se a hegemonia do cientista normal e, conseqüentemente, a configuração da ciência abstrata em períodos normais, entremeados de períodos extraordinários ou revolucionários, como exposta na teoria de Kuhn.

Um bom economista não pode ser alguém incapaz de superar uma moldura teórica ou paradigmática, de dialogar com outras correntes de pensamento, de perceber e lidar com as dimensões não-econômicas geralmente presentes na realidade, assim como com suas cambiantes especificidades. Exige-se competência no relacionar teorias com a prática, em toda sua complexidade.

Nesta linha, rejeita-se o cientista normal, apto apenas para a solução de quebra-cabeças, cuja cegueira científica é de ordem a levá-lo à perseguição e exclusão dos que não se the assemelham. Feyerabend (1980, p. 205) explicita claramente a rejeição ao reunir, de variados trechos do próprio Kuhn, qualificações como "dogmático", "autoritário", "mentalmente tacanho" e "fechado", não "um explorador do desconhecido".

Acrescenta outras tantas, por sua vez, como "o mais presunçoso tipo de especialização" (ib., p. 197), "o caráter monolítico" (ib., p. 199), "o monomaníaco" (ib., p. 201), "a estupidez profissional" (ib., p. 208), "a mais chata e a mais pedestre parte do empreendimento científico" (ib., p. 209), 
"o monístico" (ib., p. 211), "a atitude dos membros de uma sociedade fechada em relação a seu mito básico" (ib., p.212).

Nada, podemos concluir acrescentando, da concepção popular do cientista em sua busca, como nas palavras de Einstein (1981, p. 163), "a pesquisa procede por momentos distintos e prolongados, intuição, cegueira, exaltação e febre". Este é o cientista extraordinário ou revolucionário, na dicotomia kuhniana.

Na rejeição do cientista normal, a postura é na linha de Popper (1980, p. 53), o qual reconhece mas abomina a existência do fenômeno, e não aceita que se o chame normal:

O cientista 'normal', como descrito por Kuhn, tem sido mal ensinado. Ele tem sido ensinado num espírito dogmático: tem sido doutrinado[...] $\mathrm{Na}$ época [1933], [Philipp] Frank queixou-se amargamente sobre a abordagem acrítica da ciência pela maioria de seus estudantes de engenharia. Queriam 'saber os fatos' apenas. Teorias ou hipóteses que não eram 'geralmente aceitas', mas problemáticas, eram indesejadas: faziam com que ficassem desassossegados [...] Posso apenas dizer que vejo grande perigo nisso e na possibilidade de que venha a tornar-se normal (assim como vejo um grande perigo no aumento da especialização, o qual é também um fato histórico inegável): um perigo para a ciência e, de fato, para a nossa civilização ${ }^{11}$.

Feyerabend (1980, p. 198-9) acusa Kuhn de manter propositadamente uma ambigüidade positivo-normativa em seus escritos, atribuindo-a a uma estratégia de autopromoção, além de autoproteção. O problema, continua, é que isso legitima monísticos e monomaníacos nas ciências sociais, no afã de demonstrarem o caráter científico de suas disciplinas.

O modelo da Lakatos (1980), segue Feyerabend, representa melhor a evolução da ciência. Nele não se estabelecem períodos normais e revolucionários que se sucedem. O modelo reconhece a simultaneidade e a interação de um componente normal e de um componente filosófico, os quais sempre estão presentes na ciência (ib., p. 211-2):

... a ciência madura une duas tradições muito diferentes que são freqüentemente separadas, a tradição de um pluralista criticismo filosófico [a descoberta de Popper de que a ciência avança através da discussão crítica de visões alternativas] e de uma tradição mais prática [...], a qual explora as potencialidades de um dado material (de uma teoria; de um detalhe), sem ser detida pelas dificuldades que possam surgir e sem atenção para maneiras alternativas de pensar (e de agir) [a descoberta de Kuhn da importância da tenacidade, o elemento normal, conservador e anti-humanitário]

\footnotetext{
"Hayek também afirma, como citado por L undberg (1975, p. 242), que "um economista que é apenas um economista tornar-se-á provavelmente um inconveniente, se não um iminente perigo".
} 
Com raríssimas exceções, os grandes filósofos restringem-se ao estudo da ciência abstrata e, freqüentemente, apenas no campo da matéria inerte $^{12}$. Suas teorias de evolução autônoma não passam de primeiras aproximações, como por vezes reconhecem (Kuhn 1971, p. 69), já que ignoram a interação com a ciência aplicada e a prática.

Com essa explícita incorporação de Popper e de Kuhn por Feyerabend, entretanto, a teoria de Lakatos serve-nos bem para o enquadramento e avaliação do lado puro da ciência econômica, no que subsidia também a caracterização do lado social ${ }^{13}$. A propósito, surpreendemo-nos com o fato de que os participantes dessa contenda não explicitaram a necessidade da filosofia da ciência para devidamente fazê-lo.

Aplicar a filosofia, entrelaçada com o "conhecimento ordenado $e$ testado [das ciências sociais]", para usar as palavras de Kuznets (1961, p. 119), é iluminar a busca de aperfeiçoamentos da avaliação. Antes de fazêla, passamos à uma rápida consideração de algumas questões maiores.

Economia pura e social, um caso reconhecido de segmentação. $O$ marco da separação entre teorias de desenvolvimento econômico (economia social, Kuznets como exemplo) e de crescimento (economia pura, Solow) é da década de cinqüenta (Blaug 1985, p. 95).

Uma postura comum entre economistas puros filosoficamente desinformados é criticar o campo de desenvolvimento por não utilizar modelos recentes de crescimento. Cursos e publicações estariam desatualizados, bibliografias ultrapassadas, níveis de formalismo e de matematização inaceitavelmente baixos. Ora, o campo de desenvolvimento é interdisciplinar, por excelência.

$\mathrm{O}$ atendimento da crítica inviabilizaria a pesquisa em desenvolvimento, em virtude da limitação de tempo e da diferença de métodos, mesmo na ausência do problema da cegueira científica - Schumpeter (1949, p. 348) chama de ideologia científica ${ }^{14}$.

\footnotetext{
${ }^{12}$ Somos gratos a Brena Paula Magno Fernandez pela indicação de uma exceção, Bunge (1980)

${ }^{13} \mathrm{O}$ reconhecimento do caráter multiparadigmático da ciência, como enfaticamente salientado em Masterman (1980), permitir-nos-ia usar apenas Kuhn, com as próprias conexões que faz com os trabalhos de Popper e Lakatos (Kuhn 1980, p. 1-23 e p. 231-78). Por outro lado, a explicação da cegueira científica em termos de Piaget e da Gestalt é um segmento separável de sua teoria (Kuhn 1971 , p. 37, 61), que pode permanecer isoladamente em uso - Schumpeter (1949, p. 347-9), com base em Marx, seria uma alternativa doméstica, enquanto Popper $(1979$, p. 145) seria talvez mais confortável para uso dos neoclássicos.

${ }^{14} \mathrm{O}$ conflito entre economistas puros e sociais, assim como entre físicos e cientistas da engenharia, é da mesma natureza do que o conflito paradigmático entre cientistas puros durante períodos revolucionários (Silveira 1991, p. 72-3; 1993, p. 336-39). Vemos nele uma das principais causas do deslocamento de economistas sociais para fora da disciplina nos EUA, onde existem alternativas e flexibilidade institucional para tanto. Krueger et al. (1991, p. 1.039) relatam este deslocamento, mas não o explicam, como veremos abaixo. Voltaremos ao ponto na revisão de Eggertson (1995, p. 208) e Krug (1996, p. 468), no próximo artigo.
} 
A teoria de Lakatos sugere uma solução geral. Para o economista social, a exigência de teorias abstratas não deve geralmente passar do conhecimento de núcleos duros, em livros-texto especificamente desenhados segundo suas necessidades, deixando-se de fora os cintos protetores, nos quais se desenvolve o altamente perecível trabalho de fronteira dos programas de pesquisa pura.

Teorias aplicadas inaplicáveis. Sem citar Lakatos ou Kuhn em sua conferência Nobel, Stigler (1983, p. 258) fala dos componentes normais dos núcleos duros e, restritamente, da parcela dos cintos protetores que se volta para o desenvolvimento das teorias aplicadas: "Uma ciência viável e sadia exige ambas, as teorias persistentes e quase fora do tempo, que naturalmente ignoram as condições mutáveis de suas sociedades [núcleos duros], e as teorias não-estabelecidas, que encontram muita dificuldade nas tentativas de explicar os eventos correntes [cintos protetores aplicados]".

A denominação teorias não-estabelecidas, contudo, chama a atenção para a propriedade ou para limites do estudo destas teorias aplicadas na economia social. $\mathrm{O}$ vício ricardiano a partir delas significa o uso da sociedade como cobaia.

Em Schumpeter (1949, p. 345), vemos a denúncia do estado de descrédito da ciência, em virtude das "tentativas de aplicação prematura de novas teorias, na mais desencorajadora extensão". Tem-se um exemplo de "iminente perigo" do economista puro aplicado (Hayek), um exemplo também de "um perigo para a ciência e, de fato, para a nossa civilização" (Popper).

Formalismo e matematização. Precisamos ter em mente que programas de pesquisa tendem a evoluir com distanciamento cada vez maior entre os construtos e suas contrapartidas na realidade (Margenau 1966, p. 36), estendendo-se as cadeias de raciocínio na medida da fertilidade lógica dos núcleos duros.

Logo, não podemos aqui pensar em demérito porque "[a teoria] tem sido refinada a um ponto em que de fato não mais podemos aplicá-la ao mundo real" (Hayek 1969, p. 259). Precisamos então qualificar afirmações na linha da esterilidade do formalismo e da matematização da hoje observada ciência estadunidense (Kolm ib., p. 208-10). Existe uma divisão de trabalho.

A economia pura (física) e outras ciências sociais são bens de capital, são subservientes na colocação de Senior, para o desenvolvimento da economia social (ciências da engenharia). Economia social é bem de capital para o aperfeiçoamento da arte da economia e de sua prática ${ }^{15}$. A matemática e a

\footnotetext{
${ }^{15}$ Não se trata certamente da ordem de precedência histórica, a qual pode ser vista noutra tricotomia, ciências descritivas, correlativas e explicativas (Margenau, 1966, p. 29). Uma vez estabelecido o marco da ciência explicativa, as três esferas do saber evoluem de forma complementar e interativa, não obstante a cegueira científica ou o dissenso entre especialistas.
} 
própria filosofia são instrumentos ou bens de capital para a construção da ciência, nos três níveis de abstração. Tomemos a matemática.

Os construtores da álgebra de Boole, há um século e meio, não possuíam noção alguma da revolução econômica e social que sua invenção hoje realiza com a informática e seus computadores. Se tivessem que se preocupar com aplicabilidade, nada teriam construído.

$\mathrm{O}$ investimento social em teoria abstrata possui, como o da matemática aplicada, horizonte mais curto para um retorno ainda bem incerto, mas é de natureza semelhante. Georgescu-Roegen fala em conhecimento incompleto, mas o nome que se lhe dá em estratégia empresarial é mais expressivo, ignorância parcial (Silveira 1994a, p. 56).

O componente filosófico e a objetividade. Poderíamos talvez pensar, usando Kuhn, que bastaria uma avaliação do componente normal da ciência, pois o filosófico ou revolucionário viria deterministicamente a ocorrer com a acumulação das anomalias e paradoxos, os quais são involuntariamente gerados pelos solucionadores de quebra-cabeças. Em virtude do que vimos em Popper e Lakatos, entretanto, precisamos avaliá-los conjuntamente.

Diferentes paradigmas ou programas de pesquisa são necessários para o crescimento do saber. O componente filosófico da ciência abstrata é o elemento fertilizador, com suas conjecturas e refutações. O pluralismo, com diálogos e contendas entre distintas escolas de pensamento, é um investimento para a fertilização cruzada dos programas de pesquisa, assim como para delimitação da validade ou aplicabilidade de suas teorias. A interdisciplinaridade não menos.

Entendemos "o perigo da especialização", como indicado por Popper, em termos sociais, e podemos fazê-lo com a própria ajuda dele. A objetividade da ciência não reside principalmente no desapego do investigador individual, na isenção de valores ou na capacidade de superação de viés ideológico. Segundo Popper (1978, p. 23):

A objetividade pode, somente, ser explicada em termos de idéias sociais como a competição (ao mesmo tempo, de cientistas individuais e de várias escolas); tradição (principalmente a tradição crítica); a instituição social (por exemplo, a publicação em vários jornais concorrentes e através de vários editores concorrentes; discussão em congressos); o poder do Estado (sua tolerância com o debate livre).

Prosseguiremos abaixo no desenvolvimento dessas questões, consolidando outra evidência para nossa percepção de que a objetividade da ciência estadunidense está comprometida. Dada sua liderança mundial, tem-se novamente um "perigo para a ciência e, de fato, para a nossa civilização". 


\section{A comissão Krueger}

Oficialmente designada pela American Economic Association, reunindo doze representativos participantes, dois já laureados com o Nobel, esta Comissão constata perdas de meŕcado pelos recém-doutorados estadunidenses, reconhece a dificuldade deles no relacionar teoria e realidade, e chega a aventar a suspeita de que constituam uma geração com "doutosidiotas em demasia, habilitados em técnicas, mas inocentes quanto a questões econômicas reais" (Krueger et al., 1991, p. 1.044-45).

O desprovido de senso histórico (Schumpeter), o deficiente em curiosidade intelectual e aventura espiritual (Hayek), o treinado, deficiente em maturidade e senso de relevância (Portes), assim como, na medida em que estamos corretos em vê-lo tipificado no cientista normal, o doutrinado (Popper) - seria longo repetir os adjetivos de Kolm, Kuhn e Feyerabend, recebe agora a suspeita de douto idiota num consenso dos doze professores.

A Comissão aponta a causa no ensino, mas descarta o aumento de duração do curso (ib., p. 1.043) e reforça simultaneamente o currículo, com sugestões marginais ou inviáveis que só incentivariam o vício ricardiano.

Assim, recomenda aos professores do núcleo básico que exemplifiquem a teoria com casos reais (ib., p. 1.046), o que só pode ser interpretado como realidade estilizada ou "exercícios acadêmicos", para voltar à denominação de Kolm (ib., p. 210).

Recomenda em seguida aos professores dos campos que transmitam o conhecimento necessário para a ligação da teoria com a prática. Passando ao paralelo com a matéria inerte, o doutoramento em física teria que incluir o da engenharia, com substancial aumento de duração, além dos professores de física terem que dominar as ciências de engenharia!

Recém-doutorados em física não são chamados de doutos-idiotas por não saberem projetar produtos e processos. Pelo contrário, uma comissão de físicos que simplesmente evocasse uma educação para tais funções seria certamente acusada de falta de senso científico, ou até de charlatanismo.

A Comissão não revela a menor indicação ou suspeita de que a prática requer geralmente a economia social, não a teoria abstrata e seus campos. Não o faz nem quando relata "a profunda insatisfação [dos empregadores não acadêmicos] com o treinamento dos recém-formados em economia" (ib., p. 1.038). Trata-se de uma forma desconcertante de vício ricardiano, digamos uma dependência de ordem superior, pois manifestada na transmissão ou contaminação dos estudantes.

$\mathrm{O}$ ataque aos departamentos aplicados, por estarem passando a formar seus próprios doutores em economia (ib., p. 1.039), é inteiramente 
desinformado do que acima vimos sobre a filosofia da ciência. Se bemsucedido, hipótese irrealista, introduziria rigidez na flexibilidade institucional estadunidense, a qual facilita a segmentação da ciência em comunidades distintas. Popper e Feyerabend não condenam a especialização nesses termos, mas apenas o monismo teórico.

O ensino nos departamentos aplicados, disciplinas irmãs ou, ainda, campos vizinhos (Lindbeck 1985, p. 46), não exige a economia pura no rigor lógico que é importante e indispensável, mas para sua própria evolução. Vimos algo disso acima, ao considerarmos o formalismo e a separação entre os campos de crescimento e de desenvolvimento econômico.

Mais relevante, as disciplinas vizinhas não se podem dar ao luxo desse rigor lógico, pois também não possuem condições de aumentar a duração de seus cursos. O rigor aqui importante e indispensável é a acuidade, o realismo e a relevância prática dos programas.

O recém-doutorado em economia pura trabalha com cenários lógicos da realidade, uma realidade estilizada, e não aprendeu a construir atalhos logicamente plausíveis, mas não rigorosos, no conhecimento adquirido aplicando a formulação de Georgescu-Roegen (ib., p. 23-4), a economia social exige o esprit de finesse, o esprit geometrique é insuficiente. Como se não bastasse, a Comissão realça a dificuldade do recém-doutorado com a linguagem natural (ib., p. 1.049).

Parece-nos, assim, que a ênfase na técnica em detrimento da substância, oriunda na distorção causada pela facilidade das avaliações de exames matematizados, como aponta a Comissão (ib., p. 1.045), é uma questão menor perante a inadequação para uma faixa de mercado antes atendida. A inadequação do curso é a causa para a perda de mercado na prática e no ensino em disciplinas vizinhas, mais de $50 \%$ dos empregadores.

A Comissão consegue ainda ignorar que a pressão devida ao excesso de concorrência entre os estudantes, introduzida antes da fase de dissertação, exclui a curiosidade intelectual e a aventura espiritual (Hayek), excetuando-se os poucos que não se deixam conformar por inteiro. Essa exclusão é, certamente, uma das causas de estarem os cursos "sufocando a criatividade" (ib., p. 1.048).

A dimensão mais criativa da educação está muito obviamente na leitura dos clássicos em que houve criação (Kuhn 1971, p. 165), isto é, no aprendizado das teorias também através da História do Pensamento Econômico. Ao localizar e datar as teorias, a HPE estimula ainda o pluralismo. A Comissão (ib., p. 1048) limita-se a registrar, em nota de rodapé, que "muitos dos que responderam os questionários lamentaram a ausência de HPE no currículo". 
Kuhn (ib., p. 165-66) aponta essa causa ao falar do doutoramento em ciências naturais, "é uma educação estreita e rígida, mais do que provavelmente qualquer outra, exceto talvez teologia ortodoxa". Não se constitui surpresa que o caso da economia se lhe iguale nos EUA, onde o ponto não é sequer tocado por Comissão de tal nível. Vemos a doutrinação (Popper) e o monismo metodológico.

Quanto ao monismo teórico, lemos inicialmente que existe uma preocupação com a "aparente uniformidade e falta de diferenciação do produto, entre os departamentos. Todos acreditamos que grupo algum pode ou deve ditar o conteúdo da educação pós-graduada" (ib., p. 1.037). A falta de pluralismo da Comissão revela-se por completo, entretanto, na recomendação, para todos os cursos de doutorado, de um currículo básico único em micro, macro e econometria (ib., p. 1.043-46).

A Comissão discute distintos balanceamentos entre técnica e substância econômica, entre amplitude e profundidade. Discute especializações em campos distintos, mas nada sobre outras escolas de pensamento, menção alguma a ideologias. Nem parece haver mesmo necessidade de especificação da teoria neoclássica. Está subentendida! Vemos assim a exclusão do componente filosófico, o monismo e a monomania em fase monopólica.

\section{Conclusão}

Procuramos mostrar que as avaliações da ciência precisam ser iluminadas por sua filosofia. Ampliamos assim as perspectivas de três artigos que caracterizam as diferenças entre a ciência econômica nos EUA e na UE, e tipificam os posicionamentos dessa contenda. Concentramo-nos, nesse artigo, no caso estadunidense.

Nossa percepção da ciência, como conduzida nos departamentos de economia dos EUA, é de que se concentra na economia abstrata, com seus campos aplicados logicamente integrados ou em processo de integração formal. A arte e a prática da economia encontram-se então contaminadas pelo vício ricardiano.

Vemos uma especialização em economia pura, como na física, e uma expectativa da aplicação direta deste conhecimento na prática, como não ocorre na física. Não fazem economia social. Não conduzem a passagem pelo entrelaçamento do saber puro com os elementos não econômicos gerais e necessários para a ocorrência do fenômeno. 
Não levam em conta que as ocorrências envolvem cambiantes especificidades, cuja importância pode reverter as conclusões gerais. A economia social e sua arte estão se deslocando para departamentos aplicados, não sendo vistas como parte da ciência econômica. Percebemos ainda a objetividade da economia pura comprometida pela ausência de significativo componente filosófico. Prevalece o monismo, a teoria neoclássica é uma correnteza hegemônica.

$\mathrm{Na}$ atividade acadêmica da UE, pelo contrário, predominam a economia social e sua arte, determinando inclusive o nível de dedicação à esfera abstrata que se torna necessário para seus desenvolvimentos. Valoriza-se também a atividade prática do acadêmico no governo, na busca de uma política mais bem informada pela ciência econômica. Cultiva-se o pluralismo.

Observamos, entretanto, uma tendência para a americanização da ciência na UE, a qual não é explicável apenas em termos da amplitude do mercado com a crescente integração. Não parece haver uma questão de produtividade. A tese de que europeus são melhores segundo seus critérios de avaliação e estadunidenses segundo os seus soa plausível. Isso, é certo, quando se observa que o Prêmio Nobel está voltado para a economia pura e não para a concepção ampla da ciência, como mostraremos em artigo seguinte.

Prosseguiremos também com a revisão de dezessete trabalhos reunidos pelos editores da revista KYKLOS, e com a inclusão de questões não aqui analisadas, como a retórica e uma elaboração maior sobre a economia social e, conseqüentemente, sobre o caso europeu. Teremos então mais evidência para nossa percepção e mais elementos para explicar a tendência para a americanização.

De fato, esta contenda pode ser vista como versão atual da Contenda do Método, Methodenstreit. Em Silveira (1993, p. 319), analisamos aquela contenda em termos de "o primeiro grande conflito paradigmático entre economistas puros e sociais". Realizamos aqui um primeiro passo para colocação dessa no contexto daquela.

Vale antecipar um ponto, já que focalizamos neste artigo as questões do vício ricardiano e do monismo. Depois de reconhecer que o método histórico é inquestionavelmente superior na prática, Böhm-Bawerk (1890-1) faz um apelo e uma declaração em nome dos seguidores do método hipotético-dedutivo, confiando numa demonstração pelo tempo:

Confiemos no que o futuro provará. Faço apenas uma solicitação modesta, não pela aceitação cega da dedução abstrata, mas somente por uma trégua em seu 
cego repúdio, o qual se tornou moda [...] Não desejo particularmente, o que uma obstinação incompreensível ainda nos acusa de desejar, que o método hipotético-dedutivo seja posto em posição de soberania exclusiva... ${ }^{16}$

O futuro desmentiu um dos seus grandes construtores. Inverteu-se a hegemonia nessa atual contenda, numa falta de senso histórico (Schumpeter) e científico (Wagner 1886, p. 114-5):

Nada, em minha opinião, é mais prejudicial para o avanço do conhecimento que uma dada tendência dele, que ocorre ajustar-se às habilidades, inclinações, e treinamentos de acadêmicos individuais, que pode de fato ser frutífera $\mathrm{e}$ necessária, seja seguida a ponto de demandar para si mesma um controle exclusivo, e de pretender que nela está a ciência verdadeira [...] Será que é tão difícil admitir, e sobretudo para homens de ciência, que pode haver, não apenas diferenças de graus de habilidade, mas diferentes espécies de habilidades e, portanto, diferenças de inclinação, de tendência, e de uso de método? E, ademais, apreender a vantagem imensa de tais diferenças num cultivo multifacetado dos campos de conhecimento?[...] Cada tendência tem seus fortes e fracos, seus méritos e defeitos.

\section{Referências bibliográficas ${ }^{17}$}

BAUMOL, William J. 1995. "What's Different about European Economics?". KYKLOS 48 (Fasc. 2): 187-92.

BLAUG, Mark. 1985. Great Economists since Keynes. Brighton, Sussex: Harvester Press.

BÖHM-BAWERK, E. v. 1890-91. "The Historical vs the Deductive Method in Political Economy". Annals of the American Academy, vol. 1. Reproduzido em History of Economic Thought Archive: http:socserv2.socsci mcmaster.ca/"econ/ugcm/3II3/Frame 39830135.htm

BUNGE, Mario. 1980. Ciência e Desenvolvimento. Belo Horizonte: Itatiaia/ USP.

EGGERTSSON, Thráinn. 1995. "On the Economics of Economics". KYKLOS 48 (Fasc. 2): 201-10.

EINSTEIN, Albert. 1981. Como Vejo o Mundo. Rio de Janeiro: Nova Fronteira.

\footnotetext{
${ }^{16}$ Somos gratos a Antonio Henrique Pinheiro Silveira por esta referência

17 Alguns dos trabalhos listados foram traduzidos e publicados na Revista Brasileira de Economia (RBE) e/ou nas Edições Multiplic (EM), fato que está sucintamente indicado entre colchetes.
} 
FEYERABEND, Paul K. 1980. "Consolations for the Specialist". In: Lakatos, Imre and Musgrave, Alan, eds. Criticism and the Growth of Knowledge. Cambridge: Cambridge University Press.

FREY, Bruno S. and EICHENBERGER, Reiner. 1992. "Economics and Economists: A European Perspective". American Economic Review 82 (May): 216-20.

. 1993. "American and European Economics and Economists". Journal of Economic Perspectives 7 (Fall): 185-93.

GEORGESCU-ROEGEN, Nicholas. 1967. Analytical Economics. Cambridge, MA: Harvard University Press [EM I: 201-335, jun/ago. 1981 (capítulos 1 a 5)].

GROENEWEGEN, P. D., ed. 1990. Alfred Marshall on the Method and History of Economics. Sydney: Centre for the Study of the History of Economic Thought.

HAYEK, Friedrich A. von. 1969. "The Economy, Science, and Politics". In: Hayek, Friedrich A. von. Studies in Philosophy, Politics and Economics. New York: Simon and Schuster.

1975. "The Pretence of Knowledge". In Les Prix Nobel en 1974. Stockholm: Nobel Foundation. [EM II: 183-93, abr. 1982; RBE 37: 51322, out./dez. 1983].

KOLM, Serge-Christophe. 1988. "Economics in Europe and the U.S." European Economic Review 32: 207-12.

KRUEGER, Anne O, et al. 1991. "Report of the Commission on Graduate Education in Economics". Journal of Economic Literature XXIX (September): 1035-53.

KRUG, Barbara. 1996. "Comment on 'Is There a European Economics?"” KYKLOS 49 (Fasc. 3): 465-68.

KUHN, Thomas S. 1971. The Structure of Scientific Revolutions. Chicago: Univ. of Chicago Press.

. 1980. "Logic of Discovery or Psychology of Research?". In: Lakatos, Imre and Musgrave, Alan, eds. Criticism and the Growth of Knowledge. Cambridge: Cambridge University Press.

1980. "Reflections on my Critics". In Lakatos, Imre and Musgrave, Alan, eds. Criticism and the Growth of Knowledge. Cambridge: Cambridge University Press. 
KUZNETS, Simon. 1961. Six Lectures on Economic Growth. New York: Free Press of Glencoe.

LAKATOS, Imre. 1980. "Falsification and the Methodology of Scientific Research Programmes". In: Lakatos, Imre and Musgrave, Alan, eds. Criticism and the Growth of Knowledge. Cambridge: Cambridge University Press.

LINDBECK, Assar. 1985. "The Prize in Economic Science in Memory of Alfred Nobel". Journal of Economic Literature XXIII (March): 37-56.

LUNGBERG, Erik. 1975. "The Prize for Economic Science in Memory of Alfred Nobel: Speech". In Les Prix Nobel en 1974. Stockholm: Nobel Foundation.

MARGENAU, Henry. 1966. "What is a Theory?" In The Structure of Economic Science, ed. by S. R. Krup. Englewood, NY: Prentice-Hall [EM II: 289-304, ago. 1982].

MASTERMAN, Margaret. 1980. "The Nature of a Paradigm". In: Lakatos, Imre and Musgrave, Alan, eds. Criticism and the Growth of Knowledge. Cambridge: Cambridge University Press.

MCCLOSKEY, Donald N. 1983. "The Rhetoric of Economics". Journal of Economic Literature XXI (June): 481-517.

MILL, John Stuart. 1877. Essays on Some Unsettled Questions of Political Economy. London: Longmans, Green, and Co.

ONATE, Iara Vigo de Lima. 1999. A Matematização da Teoria Econômica:

Uma Abordagem Histórica. Curitiba: CMDE/UFPR (novembro), mimeo.

POPPER, Karl R. 1978. Lógica da Ciências Sociais. Rio de Janeiro: Tempo Brasileiro / Universidade de Brasília.

. 1979. "Epistemology Without a Knowing Subject". In: Popper, Karl. Objective Knowledge: An Evolutionary Approach. Oxford: Oxford University Press.

. 1980. "Normal Science and its Dangers". In: Lakatos, Imre and Musgrave, Alan, eds. Criticism and the Growth of Knowledge. Cambridge: Cambridge University Press.

PORTES, Richard. 1987. "Economics in Europe". European Economic Review 31: 1329-40. 
SCHUMPETER, Joseph A. 1949. "Science and Ideology". American Economic Review XXXIX (March): 345-59 [EM I: 129-44, fev. 1981]. . 1986. History of Economic Analysis. London: Allen \& Unwin.

SENIOR, Nassau William. 1938. An Outline of the Theory of Political Economy. London: Kimble \& Bradford.

SILVEIRA, Antonio Maria da. 1991. "A Indeterminação de Senior". Revista de Economia Política 11 (out./dez.): 70-88.

. 1993. "Wagner e Schmoller sob a Luz da Indeterminação de Senior". Estudos Econômicos 23 (mai./ago.): 319-45.

. 1994a. "Aplicabilidade de Teorias: Microneoclássica e Estratégia Empresarial". Revista de Economia Politica 14 (abr./jun.): 53-76.

. 1994b. "Teorias Econômicas: A Meia-Verdade Temporária". Revista Brasileira de Economia 48 (abr./jun.): 203-16.

. 1998a. "Avaliação do Desempenho Acadêmico: Globalização e Trópico". Revista de Ciência e Tecnologia 2 ( $\left.\mathrm{N}^{\circ} 1\right)$ : 148-62 (RECITEC http://www.fundaj.gov.br).

SILVEIRA, Antonio Maria da. 1998b. "Emulatig North American Economics: The Education for the Ricardian Vice". Stuttgart: Institut für Volkswirtschaftslehre, Universität Hohenheim, mimeo.

. 1999. "A Indeterminação de Senior: Perspectivas e Realizações de um Programa de Pesquisa". Revista de Economia 25 (23, porvindouro).

STIGLER, George F. 1959. "The Politics of Political Economists". Quarterly Journal of Economics LXXII (November): 522-37.

. 1983. "The Process and Progress of Economics". In Les Prix Nobel en 1982. Stockholm: Nobel Foundation.

WAGNER, Adolf. 1886. Systematische Nationaleconomie in the Jahrbucher fur Nationaleconomie und Statistik. Translated in the Quarterly Journal of Economics I: 113-33, "Wagner on the Present State of Political Economy". 